\title{
Mathematics and Humor: John Allen Paulos and the Numeracy Crusade
}

Paul H. Grawe

Winona State University, Winona, MN, pgrawe@hbci.com

Follow this and additional works at: https://digitalcommons.usf.edu/numeracy

Part of the Mathematics Commons, and the Rhetoric and Composition Commons

\section{Recommended Citation}

Grawe, Paul H.. "Mathematics and Humor: John Allen Paulos and the Numeracy Crusade." Numeracy 8, Iss. 2 (2015): Article 11. DOI: http://dx.doi.org/10.5038/1936-4660.8.2.11 


\title{
Mathematics and Humor: John Allen Paulos and the Numeracy Crusade
}

\author{
Abstract \\ John Allen Paulos at minimum gave the Numeracy movement a name through his book Innumeracy: \\ Mathematical Illiteracy and Its Consequences. What may not be so obvious was Paulos' strong interest in \\ the relationship between mathematics and mathematicians on the one hand and humor and stand-up- \\ comedian joke structures on the other. Innumeracy itself could be seen as a typically mathematical \\ Gotcha joke on American culture generally. In this perspective, a Minnesotan acculturated to Minnesota- \\ Nice Humor of Self-Immolation Proclivities (SImP) looks at the more raw-boned, take-no-prisoners humor \\ style Paulos outlined in Mathematics and Humor and implemented in Innumeracy. \\ Despite the difference in humor styles, there is much to applaud in Paulos' analysis of the relationship \\ between certain types of humor and professional interests of mathematicians in Mathematics and \\ Humor. Much humor relies on the sense of incongruity which Paulos' claims to be central to all humor and \\ key to mathematical reductio ad absurdum. Mathematics is rightfully famous for a sense of \\ combinatorial playfulness in its most elegant proofs, as humor often relies on clashing combinations of \\ word play. And a great range of mathematical lore is best understood within a concept of a sudden drop \\ from one sense of certainty to another (essentially a Gotcha on the audience). Innumeracy repeatedly \\ exemplifies Gotchas on the great unwashed and unmathematical majority. \\ Extensive empirical evidence over the last quarter century allows us to synthesize these Paulos \\ observations into the idea that inculcated mathematical humor has strong propensities to complex \\ Intellectual, Advocate, and Crusader humor forms. However, the Paulos humors do not include the \\ Sympathetic Pain humor form, the inclusion of which may increase teaching effectiveness.

\section{Keywords} \\ humor, jokes, comedian

\section{Creative Commons License}

\section{(i) (3)} \\ This work is licensed under a Creative Commons Attribution-Noncommercial 4.0 License

\section{Cover Page Footnote} \\ Paul Grawe received his B.A in Economics and English from Carleton College (1966), his M.A. (1967) and \\ Ph.D. (1972) from Northwestern University in English with concentrations in Shakespeare and Literary \\ Criticism. In 1968, he joined the English Department staff at Winona State University. In 1983, Nelson-Hall \\ published his Comedy in Space, Time, and the Imagination which earned Choice magazine's highest \\ rating for inclusion in college and university libraries. In recent years, he and Robin Jaeckle Grawe have \\ published additional book-length studies in Shakespearean and modern American film comedy at \\ ITCHS.org. ITCHS.org has also archived the Humor Quotient Newsletter, detailing empirical high- \\ confidence correlations between humor and sociological and psychological variables.
}




\section{Introduction: Looking Back on John Allen Paulos' Contribution to Numeracy}

The Numeracy movement is without doubt indebted to John Allen Paulos, the Temple University mathematics professor, whose book Innumeracy (Paulos 1988) made it to the best-seller lists and went through three printings in its first year.

Even on its dust jacket, Innumeracy from the very beginning took itself desperately seriously and, simultaneously, frothily humorously. The dust jacket talked about "our inability to deal rationally with very large numbers, or with the probabilities associated with them," which Douglas Hofstadter's back cover proclaimed as "a disease that has ravaged our technological society" and went on to portray Paulos as a knight errant combatting the same. "Our society would be unimaginably different if the average person truly understood [Paulos'] ideas." And lest we be at all concerned that Paulos is outside the mainstream, the dust jacket also courteously provided glowing quotations from Isaac Asimov and Simon Ramo, the co-founder of TRW.

At the same time, Innumeracy, the dust jacket proclaims, is "this brilliantly entertaining book." Paulos' "sprinkles” into his serious discussion "quirky stories and anecdotes," ranging freely over pretty much anything he wants to take a jab at.

This quirkiness is far from accidental, incidental, or inadvertent as the dedication clearly adumbrates "To Sheila, Leah, and Daniel for numberless reasons.” Paulos followed up his success with Beyond Numeracy: Ruminations of a Numbers Man (Paulos 1991) and further with A Mathematician Reads the Newspaper (Paulos 1995). These works maintained Paulos' ability to delight and instruct in mathematics simultaneously, poking fun at both an innumerate society and at least occasionally at himself and his mathematical mindset.

Thus, the first chapter of Beyond Numeracy is entitled "A Mathematical Accent” and argues something similar to the idea that lawyers as a class suffer from a condition describable as "garlic of the mind." Mathematicians too have their own strong accent which Paulos describes in terms of his irritation as a driver trying to navigate his way into New York City. The driver ahead of him stopped to help victims of a minor accident, thus causing a tie-up for Paulos and all the other drivers behind him. Paulos describes his irritation and the mathematical accent generally in a memorable sentence: "The mathematical integral or sum of the latter inconveniences [to tied-up motorists behind] was in this case greater." He concludes, "Although not a deep thought by any means, it and similar 'calculations' seem to be quite foreign to many" (3).

Beyond Numeracy is Paulos' "big book," most useful not as humor but as an introduction to useful and/or controversial mathematical topics (like chaos theory, Fibonacci series, and fractals). The book is best thought of as an overview for 
bright undergraduate mathematicians and thus as only incidentally humorous. Much more in the spirit of Innumeracy is A Mathematician Reads the Newspaper. That spirit includes numerous humorous jabs at assorted social targets, most notably jabs at the unenlightened thinking patterns of average, non-mathematical readers.

\section{Mathematics and Humor-Where It All Began}

Innumeracy was largely a second thought for Paulos. Much earlier, he had directly considered Mathematics and Humor (Paulos 1980), a small book in six chapters, the last of which, "Odds and the End," rather sums up the method and direction of the whole.

Mathematics and Humor was published by University of Chicago Press, which might intimidate those of us who are uncomfortable in the presence of many Nobel laureates. Perhaps that is why Chicago decided to lighten up on its jacket, which portrays Paulos as a stand-up comedian in straw hat and polka-dot tie holding a remote microphone and evidently keeping an audience of 13 teethily grinning numbers in stiches. (For some reason, there are more 9's in the audience than other numbers. One has to wonder what esoteric point of humor is thus illustrated, unless, of course, it happens that the 6's are so especially titillated that some of them are standing on their heads. If so, perhaps the iconography is more understandable, 6 being the long-term symbol for the imperfect human condition of which humor is often simultaneously claimed to be the epitome and the scourge.)

So with the perspective of a third of a century since these publications, it is perhaps time for someone, probably someone with a background in humor studies, to take a retrospective glance at Paulos' ideas about mathematics and humor. Put somewhat in my own terms, is there a special relationship between some forms of humor and the mathematical (mathematics professor?) personality? Paulos' style provides some quite interesting answers to this question as his formal discussion suggests ways of analyzing some forms of humor with the aid of mathematical formulations.

The opening chapter of Mathematics and Humor, which has the same name as the book as a whole, shows Paulos at his most philosophically inquisitive about an intuitive sense that humor inclinations are, in fact, related to serious professional inclinations.

From Paulos' perspective, "Both mathematics and humor are forms of intellectual play, the emphasis in mathematics being more on the intellectual, in humor more on the play" (10). And similarly at the foundation of his analysis, "logic, pattern, rules, structure" (11) are essential both to humor and to mathematics. And even further, "both mathematics and humor are economical 
and explicit" (11). Paulos' general conclusion is that "a perceived incongruity with a point and an appropriate emotional climate” provide a necessary and sufficient definition of humor (10).

Moreover, a good mathematical proof bears similarities to good humor: both rely on "cleverness and economy, playfulness, combinatorial ingenuity, and logic (particularly reductio ad absurdum)" (14).

All of these assertions rest easily within humor theory as developed since Aristotle and particularly since the Age of Reason. Saying that they rest easily within the great tradition of humor thought, however, is something separate from accepting Paulos’ position as definitive of humor generally.

For most of us, this distinction can most easily be understood by noticing that if Paulos is entirely correct in everything he claims, then humor is something of a mathematical monopoly, and mathematicians are by occupation likely to be the most humorous of all professionals. Such a reduction to absurdity suggests that Paulos is on to something, maybe onto a very great deal, but what he is on to is probably exactly his title, mathematics and humor. That is to say, there is a definite relationship between mathematics and some perspectives on humor. And thus there is some sense of humor that is appropriate to mathematics or inculcated by mathematics.

One of the things that Paulos seems to be on to is that there is a relationship between his mathematics-based perception of humor and standard stand-up nightclub comedian joke forms. This is, of course, anticipated by the dust cover cartoon of Paulos as stand-up comic.

It may be this relationship that prompts him to add, "The assertive tone of much humor seems to be largely absent in mathematics, where a more neutral or positive attitude is more common" (15). Perhaps this idea can be expanded to something like, "mathematical proofs tend to be positive in moving toward some provable truth, whereas many jokes, especially with routine night-club experience as the guide, tend toward invective, put downs, and other forms of aggressive humor.”

Again, while Paulos is on to something, it is worth noting that what he is on to is more precisely "jokes" rather than "humor," and even "performed jokes" rather than humor.

And finally, Paulos recognizes "Riddles, trick problems, paradoxes, and 'brain teasers' seem to be a bridge between humor and mathematics" (15). So not only is there a relationship between mathematics and stand-up performance jokes, but there is also a relationship between mathematics and practical jokes.

The next three chapters of Mathematics and Humor deal with specific techniques of humor that have some particular interest from mathematical perspectives. Among these is iteration or repetition which has its own fascination for mathematicians and also for certain classes of jokes, for example a cartoon of 
a tow truck pulling a tow truck, pulling a tow truck. The infinite regress created by facing mirrors has its own fascinating humor about it, and that humorous reality is probably more explored in mathematics than in any other branch of learning.

Jokes also rely strongly on axiomatic thought, on levels of diction, often on self-reference, paradox, and grammar. All of these are shared interests with mathematics.

In Chapter 5, Paulos becomes technically mathematical in the construction of a "Catastrophe Theory Model of Jokes and Humor." By this point, the equation of jokes and humor is totally explicit. Moreover, what makes a joke has essentially become that we as audience are led to expect one verbal result when, in fact, the joke leads to an entirely different conclusion. Knock-knock jokes are, of course, typically this sort of "brain-teaser," trick problem, misdirectional joke.

Paulos' model assumes a three-dimensional joke space, though presumably it could in theory be extended to four-dimensional space and beyond. The $x$ - and $y$ axes represent intensity of separate emotions or other psychological inputs. The $z$ dimension represents resulting behavior.

For certain kinds of functions relating these three variables, mathematicians rely on Thom's Theorem and the conclusion that such functions when graphed "give rise to the same general shape" (80). (As a non-mathematician, I had always assumed that this was always true for all functions, that functions of the same type, as graphed, always give rise to the same general shape.)

In any case, the general shape of Thom's Catastrophe Theorem functions is something like a split plane, one part of the plane ascending more rapidly than a second part, so that at high enough degrees of intensity of $x$ and $y$, it is almost like there are two entirely different planes. But then, the higher plane has a projecting node, nose, protuberance, or whatever, that hooks back over the lower plane. (To form such a beak takes a curve in two-dimensional space that curves back rather than proceeds forward.) For a small area out at the beak of this hooking phenomenon, there is evidently no reason why one should prefer a solution on the upper plane to a solution on the lower plane. And thus, it is possible to "fall from the higher to the lower plane," which seems a reasonable model of falling for a joke, meaning moving from a misdirected interpretation to a second, often more mundane conclusion.

“Knock, knock,” “Orange,” “-Orange who?” “Orange you glad I'm not going to tell another one?”

A great deal of mathematical insight is probably related to this catastrophic sense. For example, an instructor may ask, "What is the probability that the second card in a standard deck is the Ace of Spades?" The joke, which is supposed to educate, is that it is the same probability for the $47^{\text {th }}$ card or for the first card. 
A famous example Paulos himself discusses is of the little and naughty boy asked to stay after school for his sins and then asked to add up all the integers between 1 and 1000. Unfortunately, the boy turned out to be one of the geniuses of mathematics and came back with the answer in two minutes. The higher plane here was to sit and add 1, 2, 3, .. 1000. The naughty little boy took the short-cut of inventing the formula for such addition of integers.

Paulus also cites the joke of the bird flying between two trains initially starting 300 miles apart and both traveling at 50 miles an hour until they collide, crushing the bird, in the middle. How far did the bird fly before being crushed? You can work at it all day adding bird distances, but the short-cut, the catastrophe, is to realize that the trains will collide in exactly three hours, so the bird will have traveled its speed times three hours.

\section{From Theory to Practice-Innumeracy and Beyond}

Paulos' comments on jokes in Mathematics and Humor are actually a deeply insightful preamble to Innumeracy and to A Mathematician Reads the Newspaper, Paulos' later popularly-successful books. Even when these books are at their most serious, comparing their rhetorical strategies to what Paulos has described as humor is revealing.

Let us take, for example, Paulos' chapter "GM Trucks Explode on Side Collision: From Pity to Policy." This is an essentially serious chapter of $A$ Mathematician Reads the Newspaper, exploring a serious concern that thoughtful Americans can easily share without any mathematical proclivities of their own. The chapter also explicitly recognizes the real pain and suffering which news commentators so frequently fall all over themselves to exhibit to us in what Paulos” calls “endlessly recurring stories” (53).

The heart of Paulos' argument is that journalistic sensationalism can breed all sorts of bad policy and social evils while in no way taking seriously the issues the journalists claim to be highlighting.

I have no knowledge, for example, of the safety considerations that General Motors engineers employed when designing their trucks. It is conceivable, however, that they concluded that locating the fuel tanks outside the frame brought about a minuscule increase in the probability of a fire on impact, while significantly enhancing safety in other ways. They might have concluded that the trade-off was reasonable (84).

Now while this discussion of truck safety seems to work entirely outside joke theory, in fact, Paulos' idea of jokes is clearly present. The title of the chapter reminds us of all the grim accidents we hear about on television news and how scandalized we are all supposed to be. This is the equivalent of a joke "set-up."

The account builds with Paulos' disclaimers that he, of course, is entirely sympathetic to pain and suffering. As he is making such disclaimers, emotionally 
we as audience are led to follow the lead, to tell ourselves that we, of course, recognize and sympathize with the pain and suffering of virtually anyone. (In terms of Thom's Theorem functions, we are being led up the primrose path to the higher plane of our and journalistic superiority over GM and other Neanderthals.)

And then, a second perspective, the unexpected perspective of industrial scientists carefully measuring probabilities and calculating for all our good, is worked into the text.

As we say in the humor trade, Gotcha!

This curving back (remember the curve of a Thom's Theorem function) throws us for an emotional loop, and we end up falling from our previous sympathy with journalists and their portrayed victims to sympathizing with GM and its perhaps righteous intent. (The joke has been sprung; the misdirection is thoroughly resolved to a second plane of everyone professional having the benefit of the doubt of conscientiously doing her or his job.)

By appropriate word choice, grammar, timing, level, and the like, Paulos can make any such chapter more or less of an outright joke, more or less of a virulent humorous attack. In Innumeracy, the joke form is often quite apparent because it is we, the innumerate majority who are, in fact, the butts of the grand joke, the great unwashed in need of conversion to thinking in mathematics and getting Got when we don't. Throughout, Paulos is a master "spin doctor," very carefully calculating and manipulating the seriousness or the humorousness of texts which are essentially analyzable under Thom's Theorem.

So if you want to understand the writing talent of Innumeracy and of $A$ Mathematician Reads the Newspaper, Mathematics and Humor is an insightful guide written years in advance.

And Paulos' writing talent, we can hope, will be remembered as inciting - or shaming-Americans into mathematical literacy amidst the computational complexities of modern popular culture.

\section{Humor and Mathematics-Inculcated Humor Preference among Mathematicians}

There is, however, that other perspective I'd like to explore, what seems to have been Paulos' original fascination, the idea that mathematicians have certain propensities in humor, certain typical bents that it would be well for everyone to understand more fully.

Paulos provides great clues to this propensity. A little additional humor theory may help to organize these insights.

With Robin Jaeckle Grawe and the assistance of thousands of respondents, for the last two decades, I have been studying a small subset within humor in general, what we call "humor of the mind," recalling George Meredith's 
contribution to humor theory in "An Essay on Comedy," originally presented in 1877 (Meredith 1965). Meredith goes to the extreme of calling humor "comedy" (a good Greek word that is worth big bucks) just as Paulos goes to the extreme of calling jokes "humor" (which avoids the common and pejorative associations attached to "jokes”). But Meredith is really talking about humor, specifically humor that takes at least a momentary mental calculation in order to catch the humor.

Meredith's discussion can be seen as recognizing at least three sub-forms of mental humor. First, there is Incongruity, which Paulos early on indicates to be the center of all humor as far as he is concerned. In Incongruity, as we later empirically defined it, two things, ideas, or concepts are brought into collision with each other or into collision with a verbal structure. A drawing of a flat disk on a globe spindle and beneath the cartoon caption indicating this was Columbus' first globe is humor of this second form, a thing - a disk — collided with an ideaa globe-but collided by the choice of words in the caption.

A second Meredithian form is Word Play, two words or verbal constructions are made to collide with one another. The knock-knock Orange joke is an example, the word "Orange” colliding with “Aren't ya," which can often be pronounced similarly.

A third Meredithian form is the Gotcha joke. This needs careful definition despite all of us having a good intuitive grasp of it. Gotcha is a laughing at form of humor. Someone thinks he is smart or otherwise talented and acts on that talent. And then, it is made apparent that he wasn't that smart or otherwise talented and is Got for his effort.

Gotcha jokes have to have all these parts.

Paulos' discussion, like Meredith's, is easily analyzable as covering Incongruity, Word Play, and Gotcha humor. Unfortunately, Paulos does not clearly distinguish Gotcha from other forms of pain humor. To analyze mathematical humor, we need more sophistication about differences within pain humor. And after analysis, mathematicians might seriously consider whether Gotcha or just plain pain humor is involved in specific examples in the mathematics classroom.

\section{The Need to Take Seriously Pain in Humor}

It bears re-emphasizing: there are several types of pain humor. Gotcha is a very strictly defined subset of the more general category of pain humor.

As such, Gotcha is differentiated from pure invective, pure attack, pure pain humor. Ethnic jokes are often just straight offenses against minorities or other hated victims. Political jokes similarly are often purely malicious. Pure malicious jokes go over better if the victim isn't present or at least isn't able to fight back. 
A joke that leaves Republicans laughing in the aisles will typically only hurt the Democrat in the back row, and the same is true for a Democratic joke with either an impotent or non-present Republican butt.

Since we are talking a primarily academic area of humor, mathematician humor, it should be explicitly clear that a college classroom is a wonderfully secure place for the tenured professor to tell or do jokes on defenseless students.

The art of telling a joke over the supine bodies of those who cannot afford to object is a neglected branch of humor study generally, but it is a habit-forming reality, as, for example, in the motivational speaker I once heard who first asked his Winona, Minnesota audience (proud of its long Polish heritage) if there were any Poles in the room and then went on to announce he was telling a Polish joke anyway. (I left before finding out exactly how anti-Polish the speaker was willing to be in this amusing situation.)

In recent centuries, we have liked to think of ourselves as civilized. In discussions of humor, it is important, however, to remember basic human nature and inconvenient facts like the Roman Coliseum often being filled with laughter as gladiators were skewered. Comedian Sid Caesar based his entire career on pure pain humor. Cartoonist $\mathrm{Al}$ Capp wrote at length about pain humor underlying his own considerable achievements in Li'l Abner (Capp 1950).

Paulos seems quite at ease with pain humor, though distinctions between various types of pain humor are not central to his discussion. He himself emphasizes Freud's contributions to humor theory as I must as well.

Within a hard-headed recognition of pain as related to humor, Sigmund Freud is given the credit for articulating pain and Gotcha humor as tri-furcated rather than bi-furcated joke forms (Freud 1960). The aggressive joke has 1) a teller or author, 2) an authenticating audience, and 3) a butt. The joke only succeeds if the audience is willing to authenticate it.

In this sense, most pain humor, including Gotcha humor, has something of a bullying character. The joke author gangs up with an authenticating audience and pummels the butt. At least in theory, there is no limit on the amount of bullying and pummeling inflicted. In years since Paulos wrote, fatal attacks on schoolchildren by other students as well as student suicides have often focused on pummeling, bullying pain humor as possible contributory causes for such calamities. There is nothing in humor theory that makes such claims outlandish.

If Paulos at all dissents from a Freudian analysis here, it is in silence. However, from his comments on humor in Beyond Numeracy, it often seems that he is describing mathematicians making jokes at the expense of their classes where the primary authenticating audience is the mathematician joke author him or herself.

For example, Paulos cites the mathematician who seemed always to teach to a single exemplary and cooperative student. One day, when the instructor entered 
the class, it was evident that the exemplary student had somehow been detained from attendance that day. The mathematician turned around and left the class without any instruction, muttering to himself that there was no one present to listen. Perhaps it was not originally meant as a joke, but if it was, the joke author and authenticating audience were one.

Coming from Minnesota where Minnesota Nice is something of a cultural imperative or prerequisite, I am aware that we Minnesotans are leery of pain humor and don't appreciate tri-furcation any more than bi-furcation of jokes and instead try to uni-furcate our humor, telling jokes only on ourselves, something of a Self-Immolation Proclivity (SImP) of the Upper Midwest.

These strenuous Minnesotan SImP attempts do not refute Freud. Uni-furcating Minnesotans are only joining the teller, the authenticating audience, and the butt into one and the same person in an attempt to soften the joke. For those interested in uni-furcation, I suggest a summer or fall visit, and decidedly not a dead-ofwinter visit to Minnesota when even uni-furcation often goes into hibernation due to cabin fever.

\section{Combinational Play and Humor Personality}

If we've taken pain in humor seriously, we may be queasy about humor "personality.” As Robin Jaeckle Grawe and I have defined it technically, humor personality is a combination of humor forms. For example, if someone we know is forever telling raunchy sex jokes and graphic excremental jokes, we could analyze that humor. But I think we are all aware that we wouldn't leave it there. We'd press the analysis to an analysis of the person. And we'd almost inevitably come up with some statement like, "He has a smutty personality."

Now Paulos and many others have pointed out that mathematics often finds combinational play central to mathematical genius. It is also central to literary genius.

But even before we get further into combinational play, let us note that certainly since Freud and probably forever before him, pain humor taken separately from all other humor gets associated with bullying and pummeling. So again, it pays to pay very special attention to pain features in humor.

But now note that the last section of the present discussion seemed to wander. It had been talking about Gotcha and other pain humors. But it ended up talking about some mythical beast call uni-furcation.

"Uni-furcation" is not an example of pain or Gotcha humor; it is an example of Word Play humor. We were right to notice a shift because human beings are sensitive not just to humor in general but to discrepancies between forms of humor.

What happens when Word Play and Gotcha are used in combination? We've written at length about these combinations of mental humor forms in great 
American motion pictures. For Gotcha and Word Play, we wrote a full chapter on Disney's Aladdin (Grawe, P. et. al. 2008). Word Play is particularly prominent in Robin Williams' unforgettable Genie. Gotcha is the entire direction of the plot landing Jaffer back in the cave Genie emerged from and back in a bottle as wellGotcha!

We've called this combination of Gotcha and Word Play Advocate humor personality. Advocate has typically a no-holds-barred, my-way-or-the-highway feel. Aladdin, after all, is a boy of the streets. He's out to marry Jasmine, the sultan's daughter. There's nothing coy or shy about his and Genie's approach, nor is there anything coy about Genie's desire to be free of his bottle. The Advocate personality also routinely suggests an a priori superiority. Why should Aladdin cow tow to rules of a civil society? Why shouldn't he make a good college try for a sultan's daughter? The superiority isn't stated, it is enacted. And Advocate personality moves strongly toward the done deal, signed, sealed, and delivered, including a certified superiority of the Advocate.

Multiple uses of the same humor form are important in establishing humor personality. "Uni-furcation" is Word Play. "SImP" is another. Probably neither one is very hurtful to anyone in particular. Some would argue that failure to inflict pain makes these Word Plays only half-jokes or half-funny. One way or another, the repetition of joke form works to develop humor personality.

Now when someone chooses to emphasize Word Play and Incongruity over other mental humors, as Paulos suggests mathematicians do, that is what our empirical research shows to be Intellectual humor, a concern with words and ideas and not with people. So from a humor-of-the-mind perspective, Paulos seems to suggest that mathematicians are very Intellectual in their humor, a suggestion which seems clearly supported in all of Paulos' work.

But Paulos' catastrophe theory is essentially Gotcha in orientation, typically dependent on a Word Play like “Orange” for "Aren't ya” to prick the balloon and send us in free-fall down to the lower plane of pedestrian meaning. And Paulos' later works show strong Gotcha tendencies as well.

As already indicated, Gotcha and Word Play preferences create an Advocate humor personality, and Paulos often seems to suggest an inherent advocacy of personal superiority among mathematicians. (See Beyond Numeracy, 78-81 inter alia.)

Gotcha and Incongruity, as a third possible mathematical combination (remember Paulos' emphasis on combination for good mathematical proofs), create a Crusader humor personality. Innumeracy can rightfully claim to have launched a crusade-or at least a "campaign"-for mathematics literacy, and in general, quantification has been a long-term and iffy crusade since the early Greeks. 
(I prefer to talk in terms of a crusade, rather than a campaign for a number of reasons. Foremost, Crusader humor is involved, not Campaigner humor. Campaigners often campaign because they are paid. Crusaders are motivated by a sense of justice which demands their putting their lives on the line. This is inherent in Eisenhower's Crusade in Europe and in the Crusades for Women's Suffrage and for Civil Rights. Martin Luther King was a Crusader, not a Campaigner.)

\section{And Then There Were Four-The Tell-Tale Absence of Sympathetic Pain}

There is a fourth kind of mental humor, however, which seems unknown to Paulos, as it also seems unknown to Meredith. That form is Sympathetic Pain humor. Sympathetic Pain is another pain humor, but it is a laughing with humor.

Sympathetic Pain was included with the other three Meredithian forms of mental humor in the Humor Quotient Test (HQT) and, as already indicated HQT has since been administered to better than 4,000 respondents. HQT is composed of 42 questions each asking for a preference choice between two of the four mental humors (Grawe, R 1994.; Grawe, P. 1994). Our research shows that Sympathetic Pain appreciation grows slowly until later in life, middle age or beyond. But it becomes more and more rampant with old age, even to the doors of senility and death themselves (Grawe P. et al. 2009).

Despite the absence of recognition of Sympathetic Pain humor in Paulos, Freud, Meredith, and innumerable other humor theorists, our empirical research shows that Sympathetic Pain humor is on average about equally preferred to Gotcha, Incongruity, or Word Play for Americans between the ages of 18 and 80 (Humor Quotient Newsletter, consistent finding over all HQT reports).

In Sympathetic Pain humor, no one thought she or he was smart or otherwise talented. They are simply victims. Our typical response to Sympathetic Pain humor may be something like a laughing "That's okay, buddy, we know exactly how you feel." Sympathetic Pain humor is very inviting for us to join with the teller and the victim. We authenticate the joke exactly by joining in and associating with the butt.

Uni-furcation going into hibernation in Minnesota winter, carefully analyzed, is not only a Word Play joke. It is also a Sympathetic Pain joke that invites youespecially if you are from the South-to join us in our frigid human condition in the far North. "That's okay, buddy, we know exactly how you feel"-even though you don't know the feel of a Minnesota winter. Good jokes are quite typically multiply analyzable. The uni-furcation/hibernation joke as both Word Play and Sympathetic Pain is not Intellectual, Crusader, or Advocate. It is instead Consoler humor. 
Another Sympathetic Pain joke was a Reader's Digest joke decades ago about a harried young mother toting three toddlers through a museum cafeteria line. Getting to the desserts, she says to the server, "Three gelatins - and please, make them all the same color."

For further insight on Sympathetic Pain, we'd suggest the comedies of Gentle Will Shakespeare. He didn't get the appellation for nothing.

Currently, the most impressive comedy of Shakespeare among American audiences seems to be Midsummer Night's Dream. In Cheshire Smile (Grawe, P. et al. 2014), we devote a chapter to Midsummer and find it predominantly a combination of Gotcha and Sympathetic Pain-a tough combination. But it does marvelous things, which we call Bridgebuilder. Think about Bottom, that leadingman actor who thinks he can play any part, who then gets an ass's head, literally instead of just figuratively. That's Gotcha for you!

But-and that's always near the center of Shakespearean genius-BUT, we've also come to like Bottom. And thus, however incongruously, "We know exactly how he feels (!)" when he yearns for a good peck of oats. Midsummer Night's Dream bridges so very much, the workaday world and the supernatural, royalty and mechanic players, lovers as idiots and lovers as ideals.

Mathematician Lewis Carroll's Alice in Wonderland as children's story (rather than as symbolic or allegorical adult satire) is also internationally beloved for its Sympathetic Pain humor ambiance: “Off with their heads!!” “Yikes!!” Alice, I know exactly how you feel!

\section{Summation and Alternatives}

In summary, Paulos' work from beginning to end seems to speak to mathematician proclivities in favor of Intellectual, Advocate, and Crusader senses of humor. Perhaps in an age when society is begging for more successful mathematical education and mathematical literacy, a little more Sympathetic Pain humor would be of use in making mathematics more inviting to the masses.

The last paragraph is the conclusion: perhaps Paulus and humor theory add up to mathematicians revisiting the classroom personality of their subject. Perhaps that investigation has already taken place subsequent to Paulos' writing. As someone from literary studies, I have no special right or expertise to bring to such a reexamination and no right to assert that reexamination is currently necessary. But I can suggest humor alternatives that could be investigated.

Let's take three of the mathematical "jokes" cited earlier to exemplify Sympathetic Pain alternatives to what Paulos evidently found to be the professional ambience in mathematics three decades ago.

We have an improbable train-leading bird flying back and forth, leading two trains to inevitable fatality. The only question is when. 
It is easy to see that this is a trick question, and that mathematicians in their profession often have to find the trick in order to get a problem solved. Unfortunately, as discussed earlier, it comes off as a pain joke on the student who doesn't immediately get the point.

Is there an alternative humor approach-which turns out to also be an alternate teaching approach? And particularly a Sympathetic Pain approach?

This question should be answered, 'sure," assuredly. Unfortunately, the longterm neglect of Sympathetic Pain as a legitimate humor form makes the doing something of a trick. A little practice, like practicing the trick of the bird-train problem, should make it much easier to extemporize in a Sympathetic Pain humor vein.

The teacher sets up the back-and-forth flight situation. She or he then suggests what would be involved in calculating the first step, when will Bird meet Train B. Doing that mathematics can be an interesting review of formulating and solving simultaneous equations.

But then the instructor stops, and says something like, "Oh, golly, this is painful. Maybe more for you than for me, because I get a certain kick out of solving simultaneous equations. But look how much time this is taking, and we haven't even gotten to the part about what Train A's been doing while we worry about Bird and Train B. And you know what? This could go on forever, because Bird always has to fly back to the other train and we have to calculate just how long that takes even if at the end he is flying back and forth in nano-seconds. Oh, my heart bleeds tears for us undertaking such a gruesome assignment! Isn't there any help available to us?"

From there, students should already be smiling, knowing exactly how the instructor feels, probably even about sin and Purgatory.

And when it turns out that mathematicians are lazy and would just like quick answers, they know how that feels as well.

Moreover, when it turns out that the answer is as simple as dividing the distance by the combined train speeds and multiplying that answer in hours by the speed of Bird in miles per hour, the hallelujahs are a joint triumph of a smiling, uni-furcating teacher/student work group.

Or how about chances of the second card in the deck being the Ace of Spades? Again, this is a perfectly legitimate example of problems coming in words, words coming by themselves and not helping answer the question. There's a lot of Word Play here, but when the student falls for it, the student is Got or otherwise humiliated. Probably for the young Einstein, such humiliation was a useful stage in growing up. But for mediocre mathematicians who will eventually major elsewhere, Quantitative Reasoning quite probably isn't being inculcated by the pain.

What alternative then? 
This isn't just a joke, remember. It is a teaching moment. So how about starting off with a little teaching? "You know, when I was a student, I fell for a number of problems that could have been easily solved if I just used my head and restated the problem in a solvable way. Why, I remember Professor Grandelswanzer calling me in, calling me a dunderhead and. ...

"But then Grandelswanzer pointed out that I didn't need to fall for the question, didn't need to fall for all the words that misled me up the primrose path to the cliff. I needed to use my head to rewrite the question.”

By this point again, students should be smiling, because they know exactly how it feels to be a dunderhead. Not Al, of course. He's going on to discover Relativity anyway. But the more plebian members of the class understand, and it will help them later to do their own taxes or to see their way through a smokescreen of irrelevant verbiage in a supposedly impartial news story about some obscure statistic.

And then there's always the Fake Gotcha. "Alright class, I'm sick and tired of you all. Take out your notebooks and add every integer between 1 and 1000.”

Give the class a few seconds to be aghast. Then say, "Sounds pretty barbaric, doesn't it? Also sounds like a great waste of time, doesn't it? Well, let me tell you about a little boy who had just the same reactions you have, but also had a barbaric teacher."

Again, it is a teaching moment, not just a joke. So teach. There is a mathematical point to finding a formula. There is also a point in knowing that the summation formula is going to appear over and over again in one statistical formula after another. So one of the teaching lessons is not just how a little boy did it, but how to read a whole series of mathematical notations as a single mathematical idea, the summation of integers.

Summing up, then, yet again, we should be indebted to Paulos for trying to understand the relationship between humor and mathematics and particularly between humor and the apprehension of a mathematical personality.

But if Quantitative Reasoning is to be successful, let's get serious about pain and its relationship to humor. A Quantitative Reasoning initiative that focuses on the Albert Einsteins of the world is a bad joke. Quantitative Reasoning initiatives are vitally necessary not for $\mathrm{Al}$ and his friends, but for us poor-to-mediocre mathematicians who in the modern world are seriously disadvantaged by varying degrees of math paranoia. And for such poor-to-mediocre mathematicians, the pain of mathematical humiliation can be a close-to-insurmountable hurdle.

As teachers, we have an obligation to teach. We do not have a mandate to be humorous. Being humorous, however, does have important implications for teaching, and humor often teaches more forcefully than any other part of our teaching. 
For some, Sympathetic Pain humor, lacking the zing and sting of stand-up comedy, may be somewhat sugary. Adding a little vinegar here and there, however, can be assumed, and sweet-and-sour may be a better flavor for helping normally intelligent students across the curriculum to use math effectively. Sympathetic Pain humor is real and just as powerful as Paulos' humors. Used well, it includes rather than excludes. It can also energize, enable, and enrich.

\section{Acknowledgments}

Deep gratitude is due to the reviewers and their comments on a first draft of this paper. The paper is substantially longer and no doubt much better for their constructive help. Special thanks go to Len Vacher, who suggested the wonderful idea of turning back to John Allen Paulos' work and achievement. And repeated thanks go to Robin Jaeckle Grawe and to the thousands of responding associates of the Institute for Travesty Comedy, and Humor Studies (ITCHS ${ }^{1}$ ) whose combined preferences in humor are the base for any confidence I may have in suggesting alternative humor approaches and strategies. The unremitting encouragement and support of the entire Winona State University faculty and its students over at least five student generations is again acknowledged with greatest appreciation.

\section{References}

Capp, A.1965. The comedy of Charlie Chaplain. In Corrigan 1965, 219-229. Corrigan, R. 1965. Comedy: Meaning and form. San Francisco: Chandler Publishing Company.

Freud, S. 1960. Jokes and their relation to the unconscious. ed. J.Strachey. New York: W. W. Norton.

Grawe, P. 1994. Humor Quotient Test: Validation and results. Paper presentation to the Twelfth International Society for Humor Studies Conference. Ithaca, New York. 2008. December comedy. Institute for Travesty, Comedy and Humor Studies. http://www.itchs.org/December\%20Comedy/DC\%20ch\%206\%20.htm (accessed March 6, 2015).

— and R. Grawe. 2008. Aladdin: Do you trust me? Comedic tenor, comic vehicle: Humor in American film comedy. Institute for Travesty, Comedy, and Humor Studies. http://www.itchs.org/CTCV/ctcv\%20ch\%209.htm (accessed May 1, 2015).

\footnotetext{
${ }^{1}$ www.itchs.org (last accessed 6/1/2015).
} 
. 2009. Laughter is the best medicine: The appropriate and therapeutic use of humor in aging services settings. Paper presentation to Changing Lives: Aging Services of Minnesota Institute. Minneapolis, MN.

- 2014. A Cheshire Smile: Humor texture and personality in Shakespeare's comedies. Institute for Travesty, Comedy, and Humor Studies. http://www.itchs.org/Cheshire\%20Smile/CS\%20F\%20contents\%20A.htm (accessed May 1, 2015).

Grawe, R. 1994. Humor Quotient Test: Theoretical design. Paper presentation to the Twelfth International Society for Humor Studies Conference. Ithaca, New York. 2008. December comedy. Institute for Travesty, Comedy, and Humor Studies.

http://www.itchs.org/December\%20Comedy/DC\%20ch\%205\%20.htm (accessed March 6, 2015).

Humor Quotient Newsletter. Institute for Travesty, Comedy, and Humor Studies. http://www.itchs.org/HQN\%20contents.htm (accessed March 6, 2015).

Meredith, G. 1965. From An essay on comedy. In Corrigan 1965, 466-470.

Paulos, J. 1980. Mathematics and humor. Chicago: University of Chicago Press.

- 1988. Innumeracy: Mathematical illiteracy and its consequences. New York: Hill and Wang.

-1991. Beyond numeracy: Ruminations of a numbers man. New York: Alfred A. Knopf.

—.1995. A mathematician reads the newspaper. New York: BasicBooks. 